\title{
Vasopressin and Diabetic Kidney Disease
}

\author{
Ray El Boustany \\ Inserm UMRS 1138, Vascular Complications of Diabetes, Paris, France
}

\author{
Keywords \\ Vasopressin - Copeptin - Diabetes . \\ Diabetic nephropathy Albuminuria
}

\begin{abstract}
Background: Diabetic nephropathy has become the most common cause of chronic kidney disease (CKD). Despite the progress accomplished in therapy, the prevalence of renal disorders remains high. Some modifiable factors driving the increase in incidence of CKD, in diabetes and other settings, might have been overlooked. Consistent evidence supports a role for vasopressin, hydration state, and urine concentration in kidney health. Summary: Plasma vasopressin is elevated in diabetes, even if metabolic control is good. Several epidemiological studies have pointed to a positive association between markers of vasopressin secretion (24-h fluid intake, urine volume, plasma copeptin concentration) and renal function decline in both the community and populations at high risk of CKD, namely, diabetic patients. Research involving animal models also supports a critical causal role of the $\mathrm{V} 2$ receptor antidiuretic effects of vasopressin in the early signs of kidney disease associated with type 1 or type 2 diabetes. Key Messages: Data supporting the detrimental effects of chronic vasopressin action on the kidney is consistent in animal models and human observational studies. Since vasopressin secretion can be modulated by water intake, and its actions by selective receptor antagonists, the vasopressin-hydration system could be a potential thera-
\end{abstract}

peutic target for the prevention and treatment of diabetic nephropathy. Intervention studies are needed to examine the relevance of lifestyle or pharmacological interventions.

(c) 2018 The Author(s)

Published by S. Karger AG, Basel

Diabetic nephropathy has become the most common cause of chronic kidney disease and the first cause of dialysis initiation in the Western world, with the same trend observed in developing countries. It is well documented that circulating levels of vasopressin (i.e., antidiuretic hormone) are elevated in people with type 1 or type 2 diabetes and in animal models with spontaneous or induced diabetes [1]. The cause of increased vasopressin in diabetes is not fully elucidated; a proposed hypothesis is that these high levels result from a contraction of extracellular volume induced by glycosuria, and/or from an increased sensitivity of hypothalamic osmoreceptors to the plasma osmotic load [2]. From an adaptive perspective, increased vasopressin levels may be beneficial in the short term by limiting urine water loss induced by a higher osmolar load, mainly glycosuria. However, persistently high levels of vasopressin could also represent a risk factor for renal disease. A growing body of data supports the plausible link between vasopressin and kidney diabetic and non-diabetic disease. In humans, evidence is based on markers of hydration state and of vasopressin secretion (e.g., urine volume, urine osmolality, self-reported

\begin{tabular}{|c|c|}
\hline KARGER & $\begin{array}{l}\text { (c) } 2018 \text { The Author(s) } \\
\text { Published by S. Karger AG, Basel }\end{array}$ \\
\hline $\begin{array}{l}\text { E-Mail karger@karger.com } \\
\text { www.karger.com/anm }\end{array}$ & $\begin{array}{l}\text { This article is licensed under the Creative Commons Attribution- } \\
\text { NonCommercial-NoDerivatives } 4.0 \text { International License (CC BY- } \\
\text { NC-ND) (http://www.karger.com/Services/OpenAccessLicense). } \\
\text { Usage and distribution for commercial purposes as well as any dis- } \\
\text { tribution of modified material requires written permission. }\end{array}$ \\
\hline
\end{tabular}

Ray El Boustany, PharmD, PhD Inserm UMRS 1138 Vascular Complications of Diabetes FR-75006 Paris (France)

E-Mail ray_boustany@hotmail.com 
water intake) and plasma copeptin, the stable $\mathrm{COOH}$-terminal portion of the pre-provasopressin molecule and surrogate of vasopressin [3-13]. The likelihood of a causal relationship between elevated vasopressin and kidney function decline is strongly supported by animal models that demonstrate the pro-albuminuric effect of vasopressin in normal conditions and in diabetic nephropathy. This brief review discusses research evidence regarding a plausible link between vasopressin and kidney disease associated with diabetes.

\section{High Copeptin and Diabetic Nephropathy: Epidemiological Data}

In recent years, several independent epidemiological studies have pointed to a link between vasopressin and kidney function decline associated with diabetes. In 1,328 patients with newly diagnosed type 2 diabetes (the Dutch ZODIAC prospective study), the upper quartile of plasma copeptin concentration was associated with a faster decline of estimated glomerular filtration rate (eGFR) and with a greater increase of the urinary albumin-to-creatinine ratio during a 6.5-year follow-up [4]. In agreement with these findings, high copeptin was associated with a decline of kidney function (assessed by the eGFR) in another cohort of newly diagnosed type 2 diabetic patients (the Skaraborg-Diabetes Register) [14]. Velho et al. [15] analyzed data of 3,101 French type 2 diabetic patients from the DIABHYCAR cohort. Participants were selected on the basis of persistent micro- or macro-albuminuria without renal failure at baseline. The authors reported that the highest tertile of baseline plasma copeptin was associated with a faster decline of renal function during a 5 -year follow-up, and with an almost $300 \%$ increase in the incidence of renal events (e.g., doubling of serum creatinine, or requirement of hemodialysis or renal transplantation during follow-up) in subjects with microalbuminuria or macroalbuminuria. These associations were independent of relevant risk factors such as age, duration of diabetes, blood pressure, levels of HbAlc, albuminuria, and eGFR at baseline [15]. The link between vasopressin (or copeptin) in diabetic nephropathy is also strongly supported by studies of humans with type 1 diabetes. In 1,200 participants from the GENESIS and GENEDIAB studies (Belgian and French cohorts with long-standing type 1 diabetes), high levels of plasma copeptin were associated with an increased prevalence of established and advanced diabetic nephropathy at baseline, and with increased risk of ESRD, coronary events and all-cause mor- tality during follow-up. The association of high copeptin with the incidence of ESRD was independent of confounding factors such as age, duration of diabetes, blood pressure, HbA1c, eGFR and albuminuria at baseline [16].

\section{Vasopressin and Diabetic Nephropathy in Animal Models}

Data demonstrating the causal link between plasma vasopressin and the onset or progression of diabetic nephropathy has been accumulating over the years. The first studies involved Brattleboro rats, a strain with a spontaneous single-point mutation of the vasopressin gene that prevents normal vasopressin synthesis, and results in central diabetes insipidus. Bardoux et al. [17] reported that Brattleboro rats with streptozotocin-induced diabetes had less albuminuria and reduced kidney hypertrophy compared to control Long Evans rats with diabetes. These results support the involvement of vasopressin in the renal complications of diabetes. The role played by vasopressin, via its V2 receptor (V2R), in the early manifestations of diabetic nephropathy was highlighted by the use of a selective, non-peptide, orally active V2R antagonist (SR 121463, Sanofi Aventis) in Wistar rats with streptozotocin-induced diabetes [18]. Blockade of vasopressin $\mathrm{V} 2 \mathrm{R}$ prevented the typical rise of urinary albumin excretion. In this study, authors reported a marked interindividual variability in urinary albumin excretion and creatinine clearance, among the diabetic rats of the control group. Also, a significant correlation was observed between creatinine clearance $(r=0.675, p<0.01)$ and or albuminuria $(r=0.828, p<0.001)$ and solute-free water reabsorption $\left(\mathrm{T}^{\mathrm{c}} \mathrm{H}_{2} \mathrm{O}\right.$, the best index of the kidney's urine-concentrating activity); the early signs of diabetic nephropathy were more pronounced in rats with stronger urine concentrating activity, the latter being essentially dependent on vasopressin V2R mediated action. Overall, these findings show that rodents, like humans, display individual susceptibility to diabetic nephropathy. These findings also strongly support the involvement of the antidiuretic effects of vasopressin in the early stage of kidney disease associated with type 1 diabetes.

To evaluate if vasopressin also contributes to the renal complications of type 2 diabetes, we assessed the effect of chronic treatment with a vasopressin V2R selective antagonist (SR121463, same as used above with rats) on kidney function variables in obese $d b / d b$ mice, a classic model of type 2 diabetes [19]. The experimental groups consisted of male diabetic $(\mathrm{db} / \mathrm{db})$ and non-diabetic $(\mathrm{db} / \mathrm{m})$
18

Ann Nutr Metab 2018;72(suppl 2):17-20 DOI: $10.1159 / 000488124$
El Boustany 

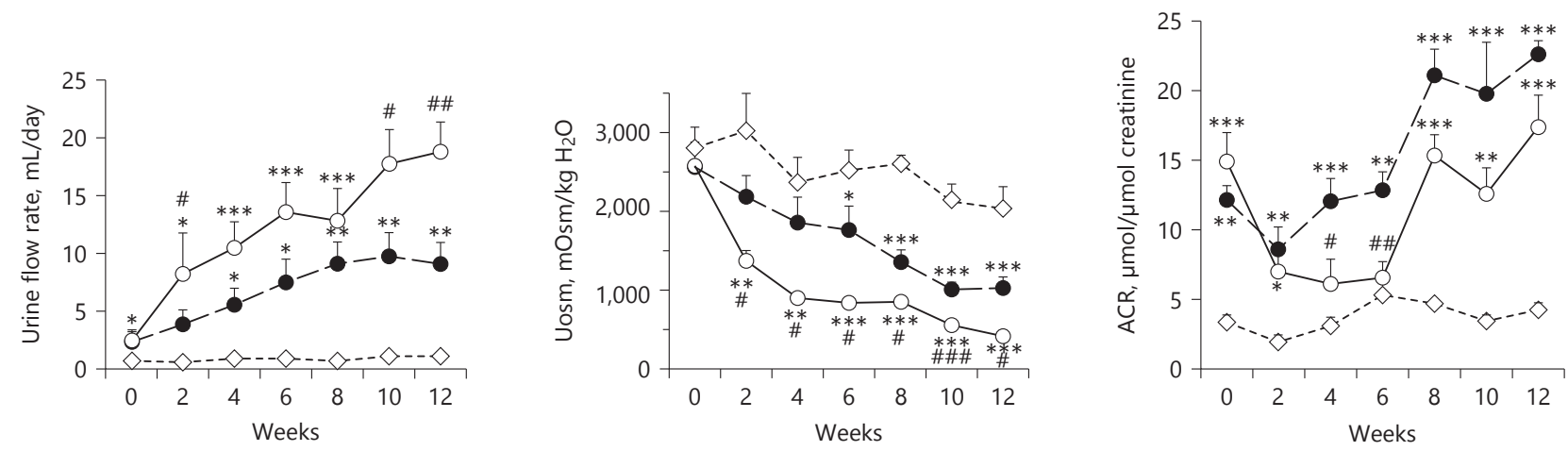

Fig. 1. Evolution of urine flow rate, urine osmolality (Uosm) and albuminuria (albumin-to-creatinine ratio, ACR) in non-diabetic mice (diamonds), non-treated diabetic $d b / d b$ mice (closed circles), and diabetic $d b / d b$ mice treated with a V2R antagonist $(30 \mathrm{mg} / \mathrm{kg} /$ day through week 8 , then $45 \mathrm{mg} / \mathrm{kg} /$ day from week 9 to 12 ; open circles). Data are expressed as mean \pm SEM. Statistics are analysis of variance for repeated measures followed by Fisher post hoc test: ${ }^{*} p<0.05,{ }^{* *} p<0.01,{ }^{* * *} p<0.001$ versus non-diabetic $d b / m$ mice. ${ }^{\#} p<0.05$, \#\# $p<0.01,{ }^{\# \# \#} p<0.001$ versus non-treated diabetic $d b /$ $d b$ mice. mice (Janvier Labs, Le Genest Saint Isle, Mayenne, France). All mice were uninephrectomized 2 weeks before the start of the experiment to increase their vulnerability of the remnant kidney to adverse events. Obese $d b /$ $d b$ mice were treated for 12 weeks with a selective V2R antagonist $(30 \mathrm{mg} / \mathrm{kg}$ per day for the first 9 weeks then 45 $\mathrm{mg} / \mathrm{kg}$ per day for the remaining 3 weeks; the drug was mixed with powdered food) and compared to non-treated obese $d b / d b$ mice. As expected, the V2R blockade resulted in a significant increase of urine output and a decrease of urine osmolality (Fig. 1). No between-group differences were observed in body weight gain, glycaemia, and blood pressure throughout the study (refer to [19] for data). The albumin-to-creatinine ratio (ACR) at baseline was similar in treated and non-treated $d b / d b$ groups; in both groups, ACR was significantly higher than in the $d b / m$ group. In non-treated $d b / d b$ mice, ACR steadily increased over time to reach $179 \%$ of baseline values at week 12. By contrast, in SR121463-treated $d b / d b$ mice, ACR initially decreased by approximately $50 \%$, remained stable for the next 4 weeks, then increased but remained significantly lower $(p=0.02)$ than in non-treated $d b / d b$ mice. Compared to $d b / m$ mice, $d b / d b$ mice experienced an elevated creatinine clearance rate, which indicated significant glomerular hyperfiltration. Creatinine clearance increased significantly across time in non-treated $d b / d b$ mice ( $409 \pm 95$ and $688 \pm 96 \mathrm{~mL} /$ day, $p<0.05$, at weeks 4 and 8 , respectively) but remained stable in treated $d b / d b$ mice ( $437 \pm 185$ and $530 \pm 226 \mathrm{~mL} /$ day, ns; Fig. 2). These results are consistent with previous type 1 diabetes find-

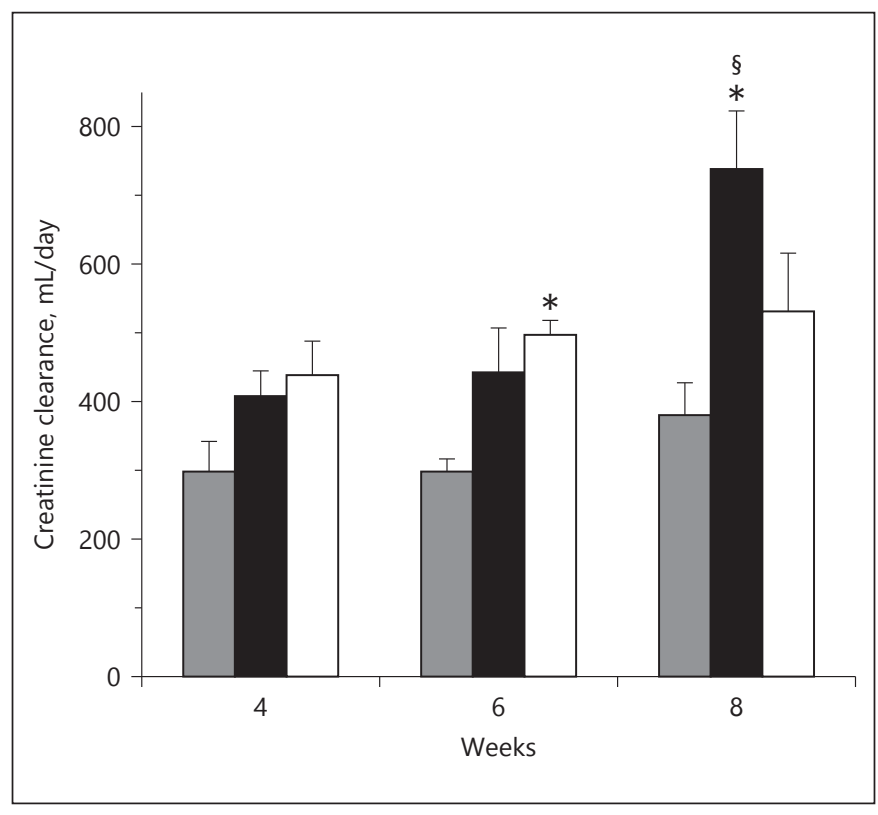

Fig. 2. Creatinine clearance at 4,6 , and 8 weeks of treatment with a V2R antagonist in non-diabetic mice (grey bars), non-treated diabetic mice (black bars), and diabetic mice treated with the $\mathrm{V} 2 \mathrm{R}$ antagonist ( $30 \mathrm{mg} / \mathrm{kg} /$ day, white bars). Data are expressed as mean \pm SEM. Statistics are analysis of variance for repeated measures and Fisher post hoc test: ${ }^{*}$ significantly different $(p<0.05)$ from $d b / m$ during the same week; ${ }^{\S}$ significantly different $(p<0.05)$ from previous weeks in the same group. 
ings, supporting a causal role for the V2R-mediated antidiuretic action of vasopressin, during the early phase of diabetic nephropathy, in animal models of both type 1 and type 2 diabetes.

Taken altogether, experimental and epidemiological data provide strong arguments regarding the detrimental effects of high levels of vasopressin/copeptin on the kidney. These data also provide a rationale for reducing vasopressin secretion and/or action on the kidney. Available tools include pharmacological blockade, and recommendations to improve drinking behaviour and hydration status. Interventional studies are thus needed to examine the relevance of these proposed lifestyle or pharmacological interventions. The effect of increasing water intake has been tested in a randomized controlled trial (WIT trial NCT01766687) involving patients with stage 3 chronic kidney disease [20]. A similar approach is needed in diabetic people with early kidney disease and high plasma copeptin concentration or deficient hydration status.

\section{Acknowledgements/Disclosure Statement}

R.E.B. was supported by a Conventions Industrielles de Formation par la Recherche (CIFRE) grant from Association Nationale de la Recherche et de la Technologie (ANRT) - France and Danone Nutricia Research. R.E.B. received reimbursement of travel expenses and registration fee to attend the 2017 Hydration for Health scientific conference.

\section{References}

1 Zerbe RL, Vinicor F, Robertson GL: Plasma vasopressin in uncontrolled diabetes mellitus. Diabetes 1979;28:503-508.

2 Zerbe RL, Vinicor F, Robertson GL: Regulation of plasma vasopressin in insulin-dependent diabetes mellitus. Am J Physiol 1985; 249(3 pt 1):E317-E325.

3 Boertien WE, Meijer E, Zittema D, van Dijk MA, Rabelink TJ, Breuning MH, Struck J, Bakker SJ, Peters DJ, de Jong PE, Gansevoort RT: Copeptin, a surrogate marker for vasopressin, is associated with kidney function decline in subjects with autosomal dominant polycystic kidney disease. Nephrol Dial Transplant 2012;27:4131-4137.

4 Boertien WE, Riphagen IJ, Drion I, Alkhalaf A, Bakker SJ, Groenier KH, Struck J, de Jong PE, Bilo HJ, Kleefstra N, Gansevoort RT: Copeptin, a surrogate marker for arginine vasopressin, is associated with declining glomerular filtration in patients with diabetes mellitus (ZODIAC-33). Diabetologia 2013;56:16801688.

5 Clark WF, Sontrop JM, Macnab JJ, Suri RS, Moist L, Salvadori M, Garg AX: Urine volume and change in estimated GFR in a community-based cohort study. Clin J Am Soc Nephrol 2011;6:2634-2641.

6 Meijer E, Bakker SJ, de Jong PE, Homan van der Heide JJ, van Son WJ, Struck J, Lems SP, Gansevoort RT: Copeptin, a surrogate marker of vasopressin, is associated with accelerated renal function decline in renal transplant recipients. Transplantation 2009;88:561-567.

7 Meijer E, Bakker SJ, Halbesma N, de Jong PE, Struck J, Gansevoort RT: Copeptin, a surrogate marker of vasopressin, is associated with microalbuminuria in a large population cohort. Kidney Int 2010;77:29-36.
8 Meijer E, Bakker SJ, van der Jagt EJ, Navis G, de Jong PE, Struck J, Gansevoort RT: Copeptin, a surrogate marker of vasopressin, is associated with disease severity in autosomal dominant polycystic kidney disease. Clin J Am Soc Nephrol 2011;6:361-368.

9 Roussel R, Matallah N, Bouby N, El Boustany R, Potier L, Fumeron F, Mohammedi K, Balkau B, Marre M, Bankir L, Velho G: Plasma copeptin and decline in renal function in a cohort from the community: the prospective D.E.S.I.R. study. Am J Nephrol 2015;42:107-114.

10 Sontrop JM, Dixon SN, Garg AX, BuendiaJimenez I, Dohein O, Huang SH, Clark WF: Association between water intake, chronic kidney disease, and cardiovascular disease: a cross-sectional analysis of NHANES data. Am J Nephrol 2013;37:434-442.

11 Strippoli GF, Craig JC, Rochtchina E, Flood VM, Wang JJ, Mitchell P: Fluid and nutrient intake and risk of chronic kidney disease. $\mathrm{Ne}$ phrology (Carlton) 2011;16:326-334.

12 Tasevska I, Enhorning S, Christensson A, Persson M, Nilsson PM, Melander O: Increased levels of copeptin, a surrogate marker of arginine vasopressin, are associated with an increased risk of chronic kidney disease in a general population. Am J Nephrol 2016;44: 22-28.

13 Torres VE, Bankir L, Grantham JJ: A case for water in the treatment of polycystic kidney disease. Clin J Am Soc Nephrol 2009;4:11401150.

14 Pikkemaat M, Melander O, Bengtsson Bostrom K: Association between copeptin and declining glomerular filtration rate in people with newly diagnosed diabetes. The Skaraborg Diabetes Register. J Diabetes Complications 2015;29:1062-1065.
15 Velho G, Bouby N, Hadjadj S, Matallah N, Mohammedi K, Fumeron F, Potier L, BelliliMunoz N, Taveau C, Alhenc-Gelas F, Bankir L, Marre M, Roussel R: Plasma copeptin and renal outcomes in patients with type 2 diabetes and albuminuria. Diabetes Care 2013;36: 3639-3645.

16 Velho G, El Boustany R, Lefevre G, Mohammedi K, Fumeron F, Potier L, Bankir L, Bouby N, Hadjadj S, Marre M, Roussel R: Plasma copeptin, kidney outcomes, ischemic heart disease, and all-cause mortality in people with long-standing type 1 diabetes. Diabetes Care 2016;39:2288-2295.

17 Bardoux P, Martin H, Ahloulay M, Schmitt F, Bouby N, Trinh-Trang-Tan MM, Bankir L: Vasopressin contributes to hyperfiltration, albuminuria, and renal hypertrophy in diabetes mellitus: study in vasopressin-deficient Brattleboro rats. Proc Natl Acad Sci U S A 1999; 96:10397-10402.

18 Bardoux P, Bruneval P, Heudes D, Bouby N, Bankir L: Diabetes-induced albuminuria: role of antidiuretic hormone as revealed by chronic V2 receptor antagonism in rats. Nephrol Dial Transplant 2003;18:1755-1763.

19 El Boustany R, Taveau C, Chollet C, Velho G, Bankir L, Alhenc-Gelas F, Roussel R, Bouby $\mathrm{N}$ : Antagonism of vasopressin V2 receptor improves albuminuria at the early stage of diabetic nephropathy in a mouse model of type 2 diabetes. J Diabetes Complications 2017;31: 929-932.

20 Clark WF, Huang SH, Garg AX, Gallo K, House AA, Moist L, Weir MA, Sontrop JM: The chronic kidney disease water intake trial: protocol of a randomized controlled trial. Can J Kidney Health Dis 2017;4: 2054358117725106. 